\title{
Reproductive and oxidative status of ewes supplemented with vitamin C during oestrous synchronization and early gestation
}

\author{
K. Pliego-Pliego ${ }^{1}$, T. Sánchez-Torres ${ }^{1 \#}$, T. Salinas-Rios ${ }^{2}$, M.M. Crosby-Galván ${ }^{1}$, C. Nava Cuéllar ${ }^{3}$, \\ J.L. Cordero Mora ${ }^{1}$, J.L. Figueroa Velasco ${ }^{1}$, A. Martínez-Aispuro ${ }^{1}$ \& M. Cárdenas-León ${ }^{4}$ \\ ${ }^{1}$ Programa de Ganadería Colegio de Postgraduados, Campus Montecillo, Texcoco, Estado de México, México \\ ${ }^{2}$ Facultad de Medicina Veterinaria y Zootecnia, Universidad Autónoma Benito Juárez de Oaxaca, Oaxaca, México \\ ${ }^{3}$ Departamento de Bioquímica, FMV-UNAM. Ciudad de México, México \\ ${ }^{4}$ Laboratorio de Biología de la Reproducción, Instituto Nacional de Ciencias Médicas y Nutrición, Tlalpan, \\ Ciudad de México, México
}

(Received 7 March 2018; Accepted 17 February 2019; First published online 27 July 2019)

\author{
Copyright resides with the authors in terms of the Creative Commons Attribution 4.0 South African Licence. \\ See: http://creativecommons.org/licenses/by/4.0/za \\ Condition of use: The user may copy, distribute, transmit and adapt the work, but must recognise the authors and \\ the South African Journal of Animal Science.
}

\begin{abstract}
The objective of the study was to evaluate the reproductive efficiency and antioxidant status of ewes supplemented with two levels of vitamin C during oestrous synchronization and early gestation. Sixty-three ewes were allocated to three treatments, namely T0: control group; T1: $3 \mathrm{~g}$ vitamin C coated with ethylcellulose (Rovimix $C^{\circledR}$, powder); and T2: $6 \mathrm{~g}$ vitamin $C$ coated with ethylcellulose. The ewes received the dietary supplementation during an oestrus synchronization period and lasted until 18 days after breeding. The occurrences of oestrus, gestation, fecundity and prolificacy were measured. Blood samples were collected at various stages to determine antioxidant capacity and oxidative state, and progesterone, glucose and insulin concentrations. Percentage occurrence of oestrus and gestation was analysed using the Chi-Square test, prolificacy and fecundity by GENMOD, and blood tests by the PROC MIXED procedure. It was recorded that the concentration of vitamin $\mathrm{C}$ in plasma increased with the supplementation of $3 \mathrm{~g}$ and $6 \mathrm{~g}$ vitamin $\mathrm{C}$. The antioxidant capacity was higher in T1 than in T0 and T2. Lipid oxidation, and glucose, insulin and progesterone concentrations were not affected. It is concluded that supplementation of $3 \mathrm{~g}$ vitamin $\mathrm{C}$ during oestrous synchronization and early gestation does not modify the reproductive responses of the ewes. However, the concentration of this vitamin in the blood increased and improved the antioxidant capacity of the animals.
\end{abstract}

Keywords: antioxidant, ascorbic acid, gestation, lipid oxidation

\# Corresponding author: teresa@colpos.mx

\section{Introduction}

The productivity of sheep depends on their ability to reproduce. Oxidative stress is one of the factors that affect reproduction negatively (Rong-Zhen \& Dao-Wei, 2013). Oxidative stress has been related to gestation disorders, spontaneous abortions, embryopathies, pre-eclampsia and low birth weights (Al-Gubory et al., 2010). It is well documented that oxidation stress increases at the time of parturition (Casamassima et al., 2012). Salinas et al. (2016) reported that at the beginning of gestation, the antioxidant capacity in blood plasma of sheep decreases. A possible explanation is that the antioxidant concentration decreases, since it has been reported that the concentration of vitamin $\mathrm{C}$, which is an antioxidant, decreases at the beginning of gestation (Salinas et al., 2017). Therefore, it is necessary to prevent this fall with antioxidant supplementation prior to breeding. Domestic animals, including ruminants, are able to synthesize ascorbic acid in the liver from glucose through the enzyme gulonolactone oxidase. Therefore, in general ruminants do not require dietary vitamin C (Combs, 2008). Although ruminants synthesize vitamin C, this lower concentration may be due to a greater demand for, or a decrease in the synthesis of this vitamin in the body. However, during vitamin C deficiency, 
successful supplementation is difficult because the vitamin is easily degraded in the rumen (MacLeod et al., 1999). Because of this, various alternatives have been evaluated to ensure that vitamin $C$ is absorbed and utilized by the animal, for example vitamin C coated with hydrogenated soybean oil (Padilla et al., 2007).

The supplementation of vitamin $\mathrm{C}$ has been investigated as a source of antioxidants in the reproductive processes of mice (Sönmez et al., 2005; Leite et al., 2017) and humans and it has been shown that ascorbic acid improves the quality of bovine follicles and their survival in in vitro culture (Thomas et al., 2001). In rats its supplementation has increased the concentration of sperm and testosterone (Sönmez et al., 2005), and also the volume, concentration and sperm motility in rabbits, and decreased mortality and abnormalities (Yousef et al., 2003). In the reproductive stage of sheep, a decrease in serum vitamin $C$ concentrations has been observed from the beginning of gestation (Salinas et al., 2017). Therefore, it is necessary to supplement sheep prior to breeding and to observe its effects on the antioxidant status, and reproductive responses. The objective of this research was to evaluate the reproductive efficiency and antioxidant status of ewes supplemented with two levels of vitamin $\mathrm{C}$ coated with ethylcellulose during oestrous synchronization and early gestation.

\section{Materials and Methods}

The investigation was performed on the experimental ovine farm of Colegio de Postgraduados, located at $19029^{\prime} \mathrm{N}$ and $98053^{\circ} \mathrm{O}$, with an annual average temperature of $15.2^{\circ} \mathrm{C}$ and an annual rainfall of $636.5 \mathrm{~mm}$ (García, 2004). The management of the animals was carried out according to the rules of Animal Welfare, Biosafety and Ethics of this institution, in accordance with official Mexican standard NOM-062-ZOO-1999 (SAGARPA, 2001).

Sixty-three multiparous Suffolk-Dorset crossbreed ewes were used, with an average live weight of $60 \pm$ $5.18 \mathrm{~kg}$ and body condition of 3 on a scale of 1 to 5 . The ewes were allocated in a completely randomized design to three treatments with 20 ewes per treatment. The treatments were: T0: control; T1: $3 \mathrm{~g}$ vitamin C coated with ethylcellulose (Rovimix C) and T2: $6 \mathrm{~g}$ vitamin C coated with ethylcellulose (Rovimix C). Supplementation started when a vaginal progesterone-releasing device $\left(\mathrm{CIDR}^{\circledR}\right)$ was inserted until a day prior to pregnancy diagnosis (Figure 1 ).

The ewes were fed according to the nutritional requirements of the NRC (1985), and received oat hay (free access) and supplemented with $250 \mathrm{~g}$ of a concentrate per day (Table 1). The concentrate and vitamin C were fed individually by housing the ewes in individual pens from 8:00 to 10:00 each day, and then as a group in a common pen where the oat hay was supplied.

Table 1 Composition of the concentrate provided to the ewes during oestrus synchronization and at beginning of pregnancy

\begin{tabular}{lc}
\hline Ingredients & $\%$ \\
\hline Sorghum & 75.82 \\
Soybean paste & 6.94 \\
Oat hay & 9.91 \\
Molasses & 5.35 \\
Salt minerals* & 1.98 \\
Total & 100.00 \\
Total composition & \\
Dry matter & 88.69 \\
Crude protein & 11.1 \\
ME (Mcal/kg) & 2.77 \\
Crude fibre & 26.45 \\
Ash & 4.29
\end{tabular}

* Phosphorus (17.5\%), sodium (12.9\%), calcium 5.6\%, magnesium 3.4\%.

ME: metabolizable energy 


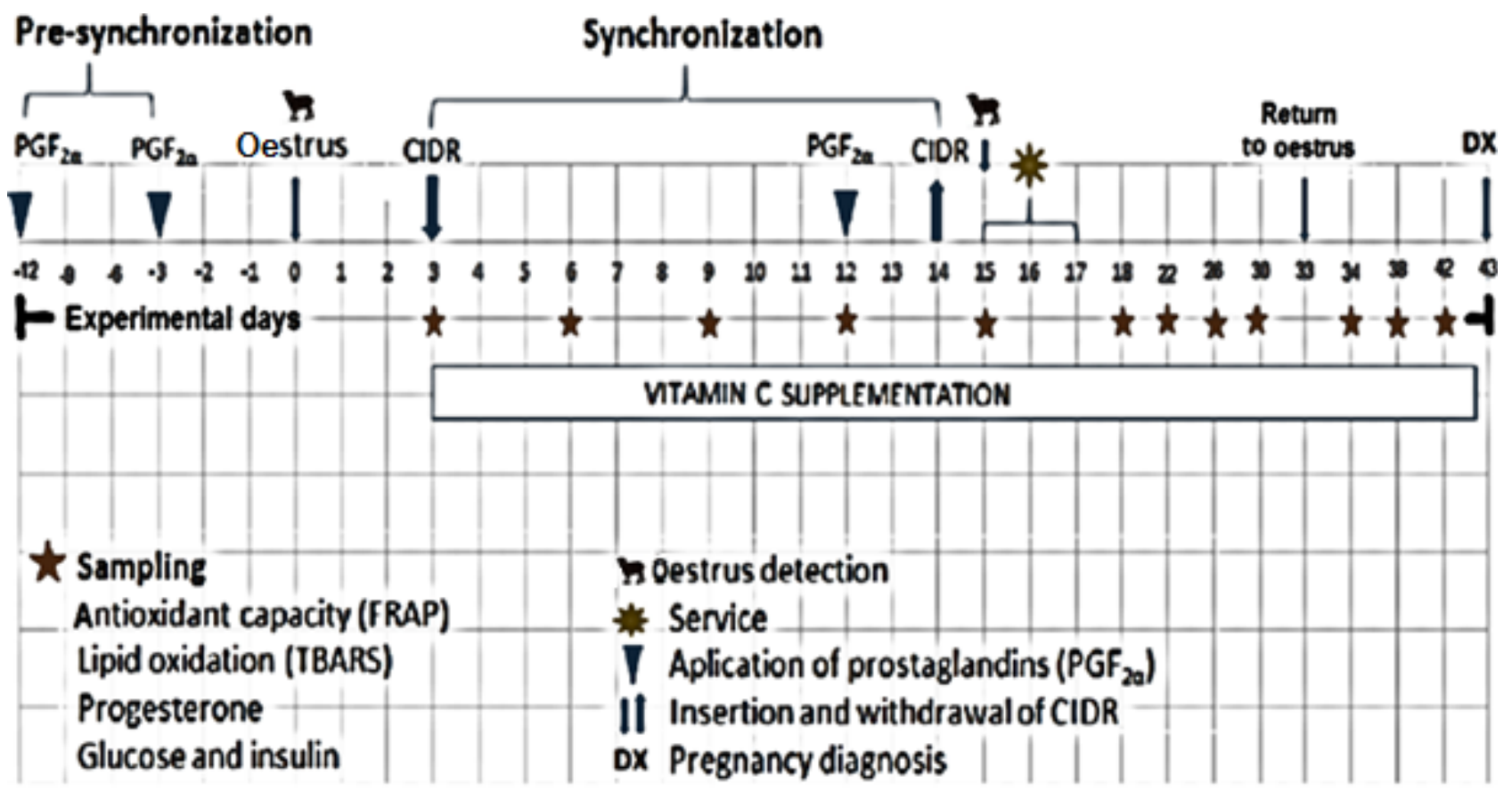

Figure 1 Oestrus synchronization protocol and sampling realized during vitamin $C$ supplementation CIDR: vaginal progesterone-releasing device, $\mathrm{PGF}_{2 a}$ : prostaglandin, TBARS: reactive substances to the thiobarbituric acid, FRAP: ferric reducing ability of plasma

To ensure that all the ewes were in the same reproductive phase at the time of oestrous synchronization, presynchronization was performed with two doses of prostaglandin $F_{2} \alpha$ (79.5 $\mu \mathrm{g}$ of cloprostenol sodium, Celosil $\left.^{\circledR}\right)$ nine days apart. All of the ewes showed oestrus in response to the second dose of prostaglandin. On the sixth day after the second dose of prostaglandin, an intra-vaginal device (CIDR), which was impregnated with $0.3 \mathrm{~g}$ progesterone, was inserted, and remained intravaginally for 11 days. Forty-eight hours before the withdrawal of this device, $79.5 \mu \mathrm{g}$ cloprostenol sodium was injected per ewe. Twelve hours after the CIDRs were removed, oestrous detection began with the aid of rams equipped with fitted aprons. The mating of the ewes that showed oestrus was performed with 10 rams of the same breed, 8 and 16 hours after heat detection. Any returns to oestrus were detected 17 days after mating (Figure 1).

Pregnancy diagnosis was made 30 and 60 days after mating, using a real-time Sonovet 600 imaging ultrasound with a 7.5 Mhz transrectal linear transducer (Medison, Cypress, California, USA). To determine the percentage of gestation, the number of ewes diagnosed as pregnant was divided by the number of ewes that were bred. Fecundity was measured by dividing the number of lambs born by the total number of ewes per treatment, and prolificacy by dividing the number of lambs born by the number of lambed ewes. All the lambs were weighed within 12 hours of lambing.

Blood samples were collected in vacutainer tubes through jugular vein puncture $(5 \mathrm{~mL})$ at 8:00 to determine progesterone concentration $\left(\mathrm{P}_{4}\right)$. Two hours after supplementation with vitamin $\mathrm{C}$, an additional sample was collected into EDTA tubes for the subsequent determination of antioxidant capacity, lipid oxidation and vitamin $\mathrm{C}$ concentration (Figure 1). All samples were centrifuged at $1500 \mathrm{~g}$ for 15 minutes at $4{ }^{\circ} \mathrm{C}$. The blood plasma was separated and deposited in Eppendorf tubes, which were stored at $-40^{\circ} \mathrm{C}$ until analysis.

Total antioxidant capacity was measured using the FRAP (ferric reducing ability of plasma) technique of Benzie \& Strain (1999). Lipid oxidation was measured by testing thiobarbituric acid reactive substances (TBARS) according to the procedure described by Ohkawa et al. (1979). The analysis of ascorbic acid was performed according to the technique described by Jacota \& Dani (1982) with some modification, which consisted of placing $3.2 \mathrm{~mL}$ of $10 \%$ trichloroacetic acid and adding $800 \mu \mathrm{L}$ of plasma, vigorously shaking for 5 seconds, and leaving it to incubate for 5 minutes in ice-water.

Progesterone concentrations were measured, using an immunoenzymatic assay (Immunometrics, UK, Ltd, 280 Muster Road, London SW6 6BQ). The analytical sensitivity was $0.13 \mathrm{ng} / \mathrm{mL}$ with intra- and inter-assay 
coefficients of $9.59 \%$ and $13.7 \%$, respectively. Insulin concentrations were determined by a radioimmunoassay technique (RIA) with a sensitivity of $4.09 \mathrm{ng} / \mathrm{mL}$ and intra- and inter-assay variation coefficients of 1.44 and $0.25 \%$, respectively. To determine plasma glucose concentration, a colorimetric enzymatic method was used with reagents of Pointe Scientific brand (Pointe Scientific Inc. Canton Mi. USA) and a Mindray BS-200 automated clinical biochemistry analyser (Shenzhen Mindray Bio-Medical Electronics Co., Ltd., Shenzhen, China).

The percentages of oestrus onset, return to oestrus and gestation were analysed using a Chi-Square test, according to the PROC FREQ procedure. For the variables of prolificacy and fecundity, a Poisson regression statistical model was used, using the GENMOD procedure. For the weight at birth, the Tukey means comparison test was applied, using the PROC GLM procedure.

Measurements of progesterone, insulin, antioxidant capacity, oxidative state and ascorbic acid were analysed with analysis of variance using the PROC MIXED and Tukey's comparison test. All procedures were analysed with the SAS statistical analysis system package, version 9.0 (SAS, 2002). A Tukey test was performed for the variables that showed a significant difference $(P<0.05)$.

\section{Results}

Supplementing the ewes with $3 \mathrm{~g}$ or $6 \mathrm{~g}$ vitamin $\mathrm{C}$ per day did not affect the percentage occurrence of oestrus, gestation, prolificacy and fecundity, and weight of the lambs at birth. In all the treatments, the gestation percentage was higher than $90 \%$. The percentage of ewes did not change at 30 and 60 days of gestation or parturition. There were no pregnancy losses after the observation of return to oestrus (Table 2).

Table 2 Reproductive variables in synchronized ewes supplemented with two levels of coated vitamin C during oestrus synchronization and beginning of pregnancy

\begin{tabular}{lcccc}
\hline & T0 & T1 & T2 & P-value \\
\hline Oestrus (\%) & 100 & 100 & 100 & \\
Return of oestrus (\%) & 9.5 & 9.5 & 0 & 0.6333 \\
30 days gestation (\%) & 90.5 & 90.5 & 100 & 0.9986 \\
60 days gestation (\%) & 90.5 & 90.5 & 100 & 0.9986 \\
Prolificacy (\%) & 1.47 & 1.37 & 1.38 & 0.956 \\
Fecundity & 1.33 & 1.24 & 1.38 & 0.919 \\
Weight of lamb at birth (kg) & 4.40 & 4.87 & 4.68 & 0.3268 \\
\hline
\end{tabular}

T0: $0 \mathrm{~g}$ vitamin C; T1: $3 \mathrm{~g}$ vitamin C; T2: $6 \mathrm{~g}$ vitamin C

It was observed that the concentration of ascorbic acid in blood plasma increased $(P<0.05)$ with supplementation of vitamin C. However, when evaluating the inclusion level, a similar blood concentration was observed when it was supplemented with 3 or $6 \mathrm{~g}$ vitamin C coated with ethylcellulose (Table 3), while through the samplings, it was observed that, in general, from the application of prostaglandin (two days before the withdrawal of CIDR) and until day 21 of gestation, the concentrations decreased (Figure 2).

The antioxidant capacity was higher $(P<0.5)$ in ewes supplemented with $3 \mathrm{~g}$ vitamin $\mathrm{C}$ per day than the control group and those supplemented with $6 \mathrm{~g}$ vitamin $\mathrm{C}$ (Table 3). This was modified by stage of sampling, without presenting a clear tendency stage of the synchronization of oestrus and early gestation, where a marked period of increase or decrease was observed (Figure 3). 
Table 3 Means \pm SE of antioxidant capacity, lipid oxidation, glucose, insulin and ascorbic acid concentrations in plasma of sheep supplemented with vitamin C coated with ethylcellulose during oestrus synchronization and beginning of gestation

\begin{tabular}{lcccccc}
\hline Treat & $\begin{array}{c}\text { Ascorbic acid } \\
(\boldsymbol{\mu} \mathbf{g} / \mathrm{mL})\end{array}$ & $\begin{array}{c}\text { FRAP } \\
(\mathbf{n m o l} / \mathbf{m L})\end{array}$ & $\begin{array}{c}\text { MDA } \\
(\mathbf{n m o l} / \mathbf{m L})\end{array}$ & $\begin{array}{c}\text { Glucose } \\
(\mathbf{m g} / \mathbf{d L})\end{array}$ & $\begin{array}{c}\text { Insulin } \\
(\mathbf{n g} / \mathbf{m L})\end{array}$ & $\begin{array}{c}\text { Progesterone } \\
(\mathbf{n g} / \mathbf{m L})\end{array}$ \\
\hline & & & & & & \\
T0 & $10.79^{\mathrm{b}} \pm 0.52$ & $246.0^{\mathrm{b}} \pm 6.85$ & $7.32 \pm 0.49$ & $67.0^{\mathrm{a}} \pm 1.03$ & $0.50 \pm 0.05$ & $4.28 \pm 0.26$ \\
T1 & $12.97^{\mathrm{a}} \pm 0.49$ & $284.1^{\mathrm{a}} \pm 7.04$ & $7.74 \pm 0.51$ & $60.26^{\mathrm{b}} \pm 1.09$ & $0.52 \pm 0.05$ & $4.29 \pm 0.28$ \\
T2 & $12.84^{\mathrm{a}} \pm 0.51$ & $261.7^{\mathrm{b}} \pm 6.45$ & $8.74 \pm 0.47$ & $67.4^{\mathrm{a}} \pm 0.98$ & $0.56 \pm 0.04$ & $4.76 \pm 0.25$
\end{tabular}

${ }^{a, b}$ Different superscripts within columns indicate significant differences $(P<0.05)$

Treat: treatments; T0: $0 \mathrm{~g}$ coated vitamin C; T1: $3 \mathrm{~g}$ coated vitamin C; T2: $6 \mathrm{~g}$ coated vitamin C

FRAP: ferric reducing antioxidant power; MDA: malondialdehyde

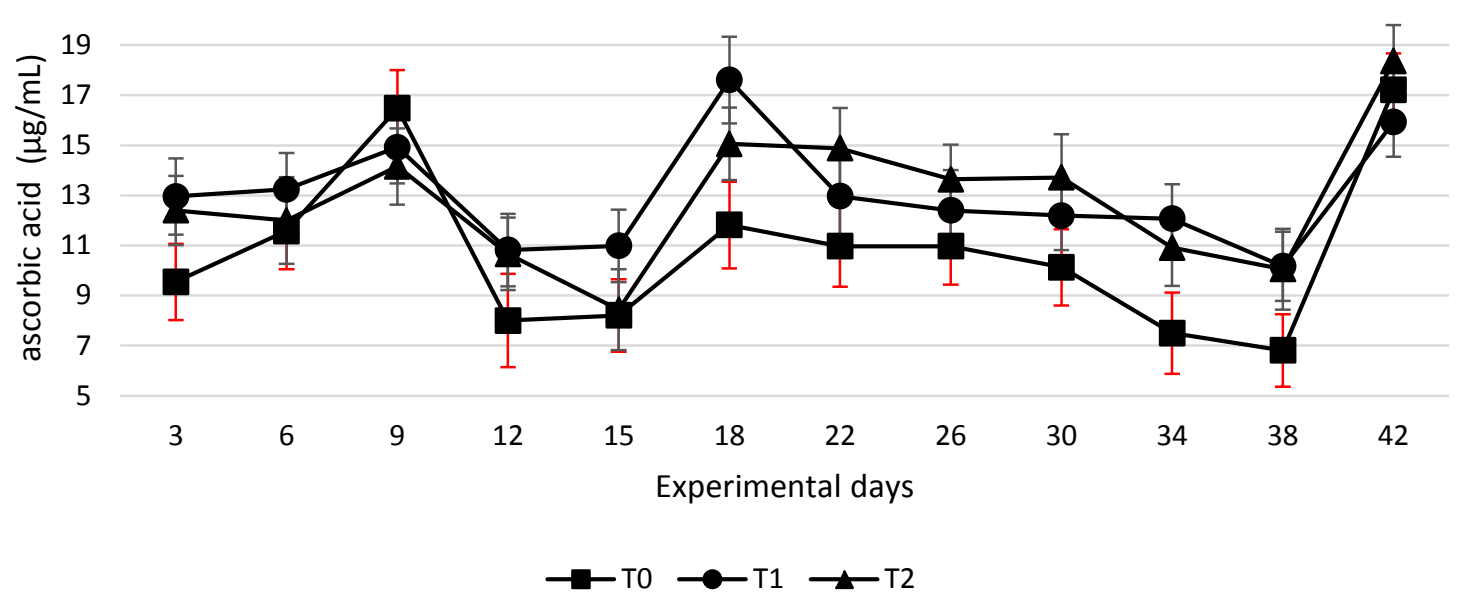

Figure 2 Plasma concentration of ascorbic acid in ewes during oestrus synchronization and start of gestation Sampling: 3 (CIDR, insertion); 6 (3 days with CIDR); 9 (6 days with CIDR); 12 (application of PGF 2 ); 15 (detection of oestrus, mounts); 18 (one day of gestation); 22 (5 days of gestation); 26 (9 days of gestation); 30 (13 days of gestation); 34 (17 days of gestation); 38 (21 days of gestation); 42 ( 25 days of gestation).

T0: $0 \mathrm{~g}$ of vitamin C; T1: $3 \mathrm{~g}$ of vitamin C; T2: $6 \mathrm{~g}$ of vitamin C

CIDR: vaginal progesterone-releasing device

The concentrations of malondialdehyde (which is formed by the lipid peroxidation of unsaturated fatty acids) and insulin were not modified by vitamin C supplementation (Table 3) or by sampling (Figures 4 and 6). The glucose concentration was lower in T1 than in T0 and T2 (Table 3). Progesterone concentration in plasma followed a normal pattern, where the concentrations increased when the sheep had progestogen present, and decreased after the removal of the device. From day 22, which corresponds to four days after mating, the concentrations of progesterone began to increase until above $5 \mathrm{ng} / \mathrm{mL}$ in sampling of day 30 and remained high to maintain gestation (Figure 7). 


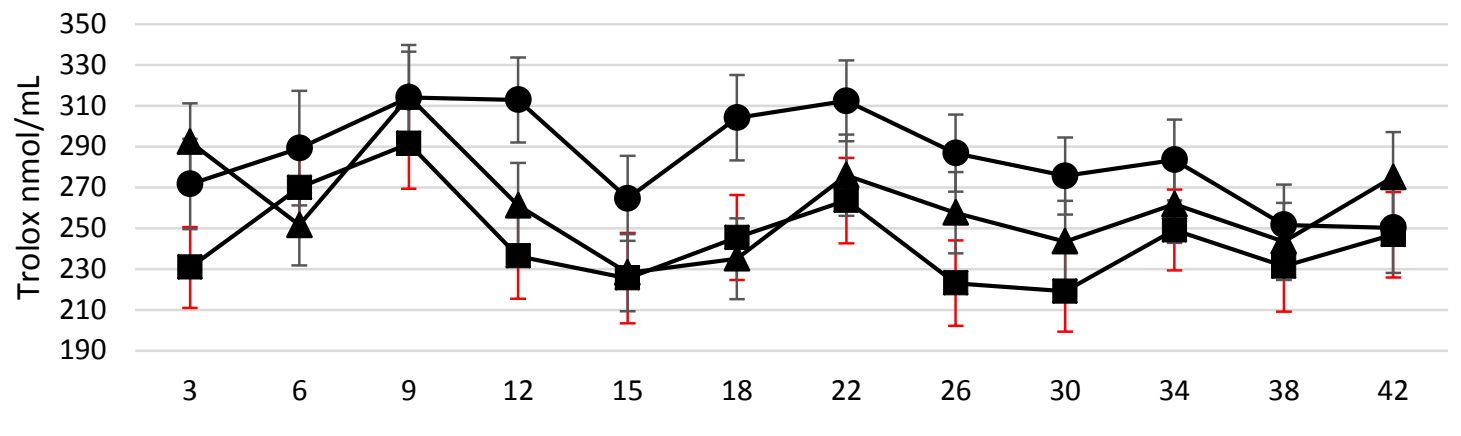

Experimental days

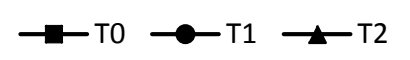

Figure 3 Antioxidant capacity as (Trolox: a water-soluble analogue of vitamin E) in ewes supplemented with coated vitamin $C$ during oestrus synchronization and start of pregnancy

Sampling: 3 (CIDR insertion); 6 ( 3 days with CIDR); 9 ( 6 days with CIDR); 12 (application of PGF 2 ); 15 (detection of oestrus, mounts); 18 (one day of gestation); 22 (5 days of gestation); 26 (9 days of gestation); 30 (13 days of gestation); 34 (17 days of gestation); 38 (21 days of gestation); 42 (25 days of gestation).

T0: $0 \mathrm{~g}$ of vitamin C; T1: $3 \mathrm{~g}$ of vitamin C; T2: $6 \mathrm{~g}$ of vitamin C

CIDR: vaginal progesterone-releasing device

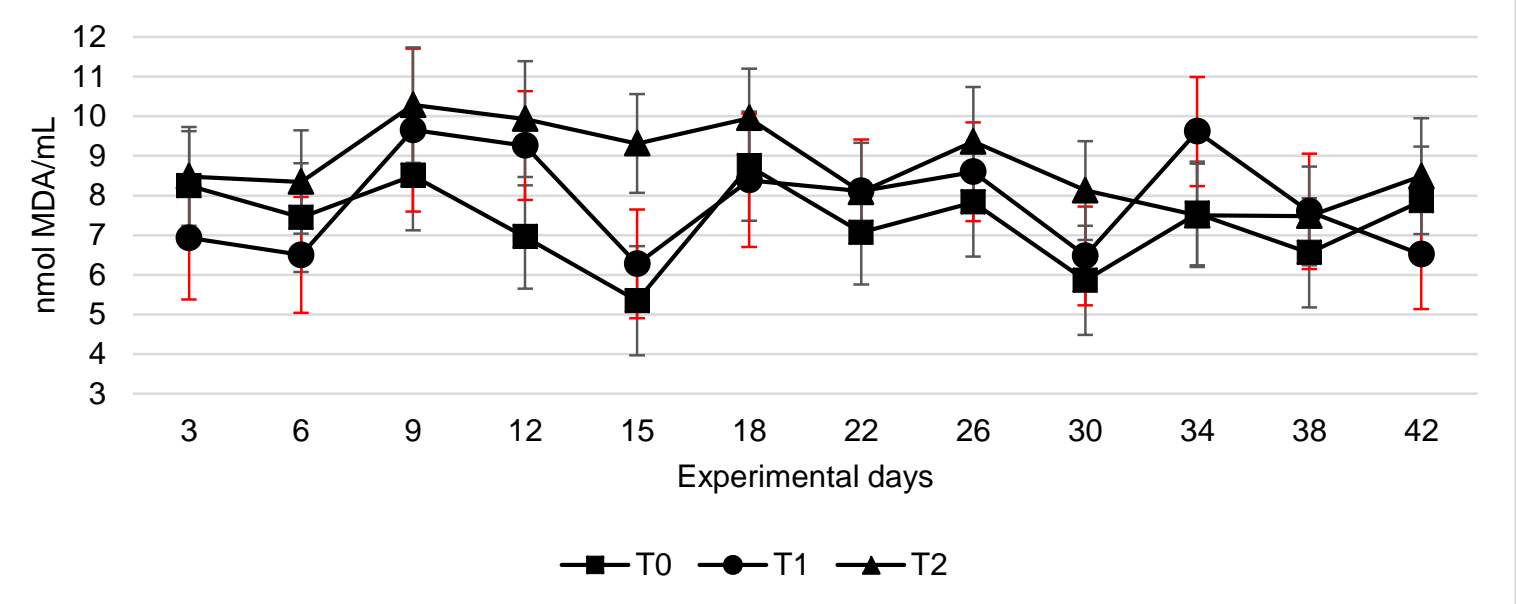

Figure 4 Lipid oxidation in ewes supplemented with coated vitamin C during oestrus synchronization and start of gestation (MDA: malondialdehyde)

Sampling: 3 (CIDR insertion); 6 ( 3 days with CIDR); 9 (6 days with CIDR); 12 (application of PGF 2 ); 15 (detection of oestrus, mounts); 18 (one day of gestation); 22 (5 days of gestation); 26 (9 days of gestation); 30 (13 days of gestation); 34 (17 days of gestation); 38 (21 days of gestation); 42 (25 days of gestation).

T0: $0 \mathrm{~g}$ of vitamin C; T1: $3 \mathrm{~g}$ of vitamin C; T2: $6 \mathrm{~g}$ of vitamin C

CIDR: vaginal progesterone-releasing device 


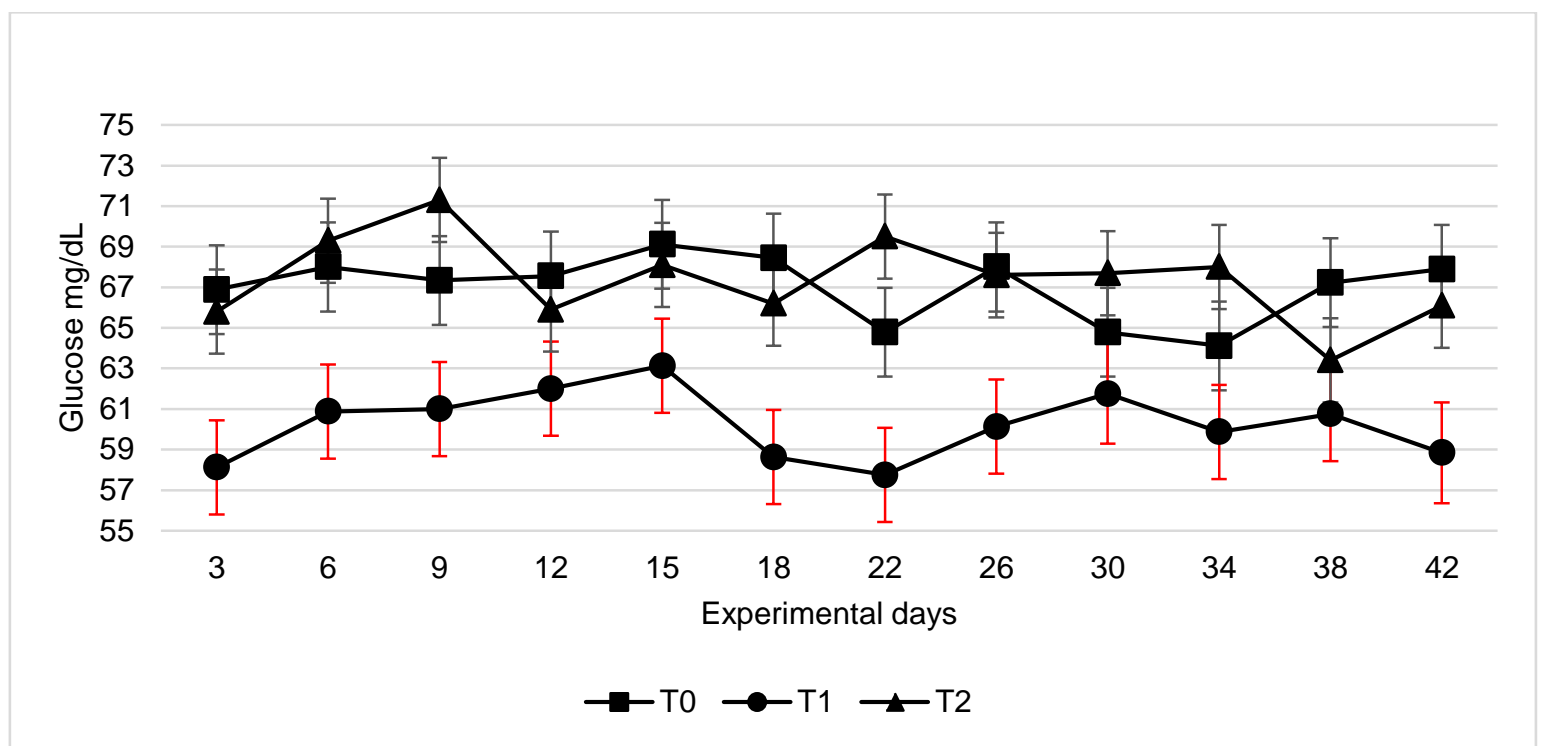

Figure 5 Plasma glucose concentration in ewes supplemented with coated vitamin C during oestrus synchronization and start of pregnancy

Sampling: 3 (CIDR insertion); 6 (3 days with CIDR); 9 (6 days with CIDR); 12 (application of PGF $2 \alpha$ ); 15 (detection of oestrus, mounts); 18 (one day of gestation); 22 (5 days of gestation); 26 (9 days of gestation); 30 (13 days of gestation); 34 (17 days of gestation); 38 (21 days of gestation); 42 (25 days of gestation).

T0: $0 \mathrm{~g}$ vitamin C; T1: $3 \mathrm{~g}$ vitamin C; T2: $6 \mathrm{~g}$ vitamin C

CIDR: vaginal progesterone-releasing device

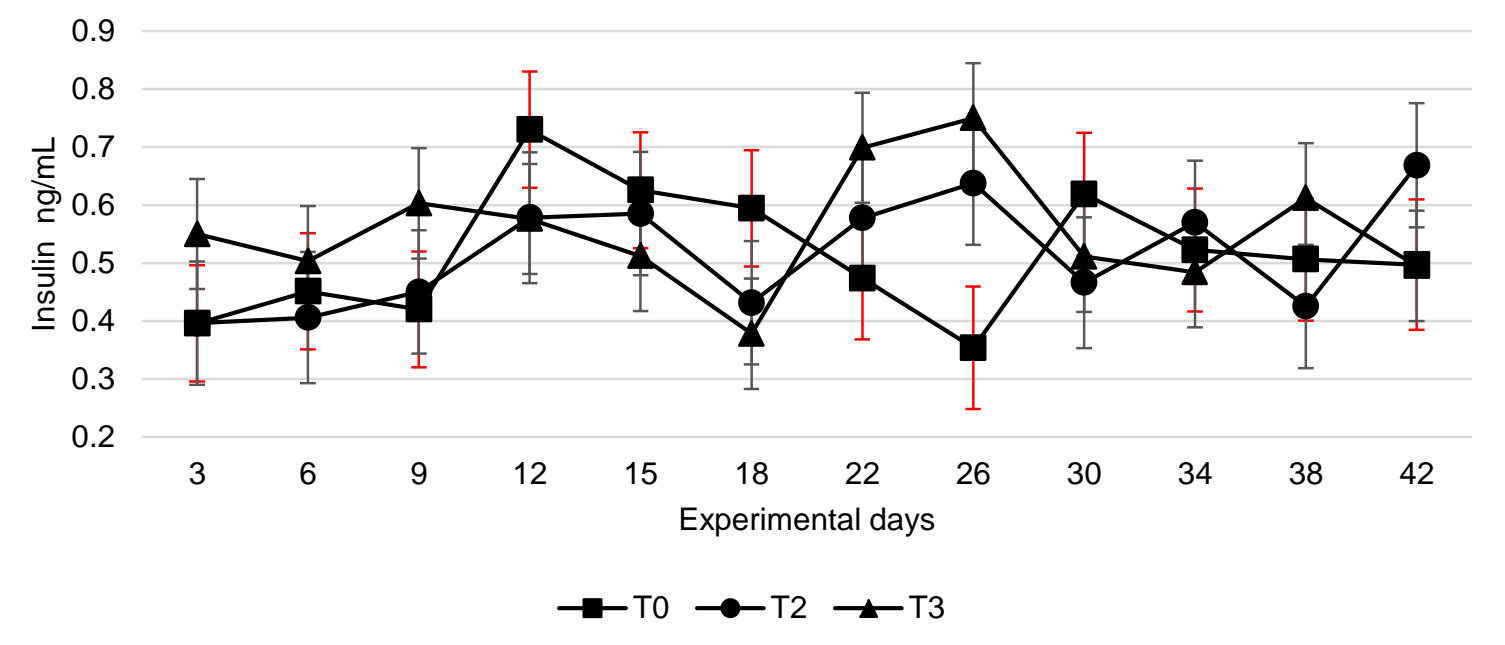

Figure 6 Concentration of insulin in plasma of ewes supplemented with coated vitamin C during oestrus synchronization and start of pregnancy

Sampling: 3 (CIDR insertion); 6 ( 3 days with CIDR); 9 (6 days with CIDR); 12 (application of PGF 2 ); 15 (detection of oestrus, mounts); 18 (one day of gestation); 22 (5 days of gestation); 26 (9 days of gestation); 30 (13 days of gestation); 34 (17 days of gestation); 38 (21 days of gestation); 42 (25 days of gestation).

T0: $0 \mathrm{~g}$ vitamin C; T1: $3 \mathrm{~g}$ vitamin C; T2: $6 \mathrm{~g}$ vitamin C

CIDR: vaginal progesterone-releasing device 


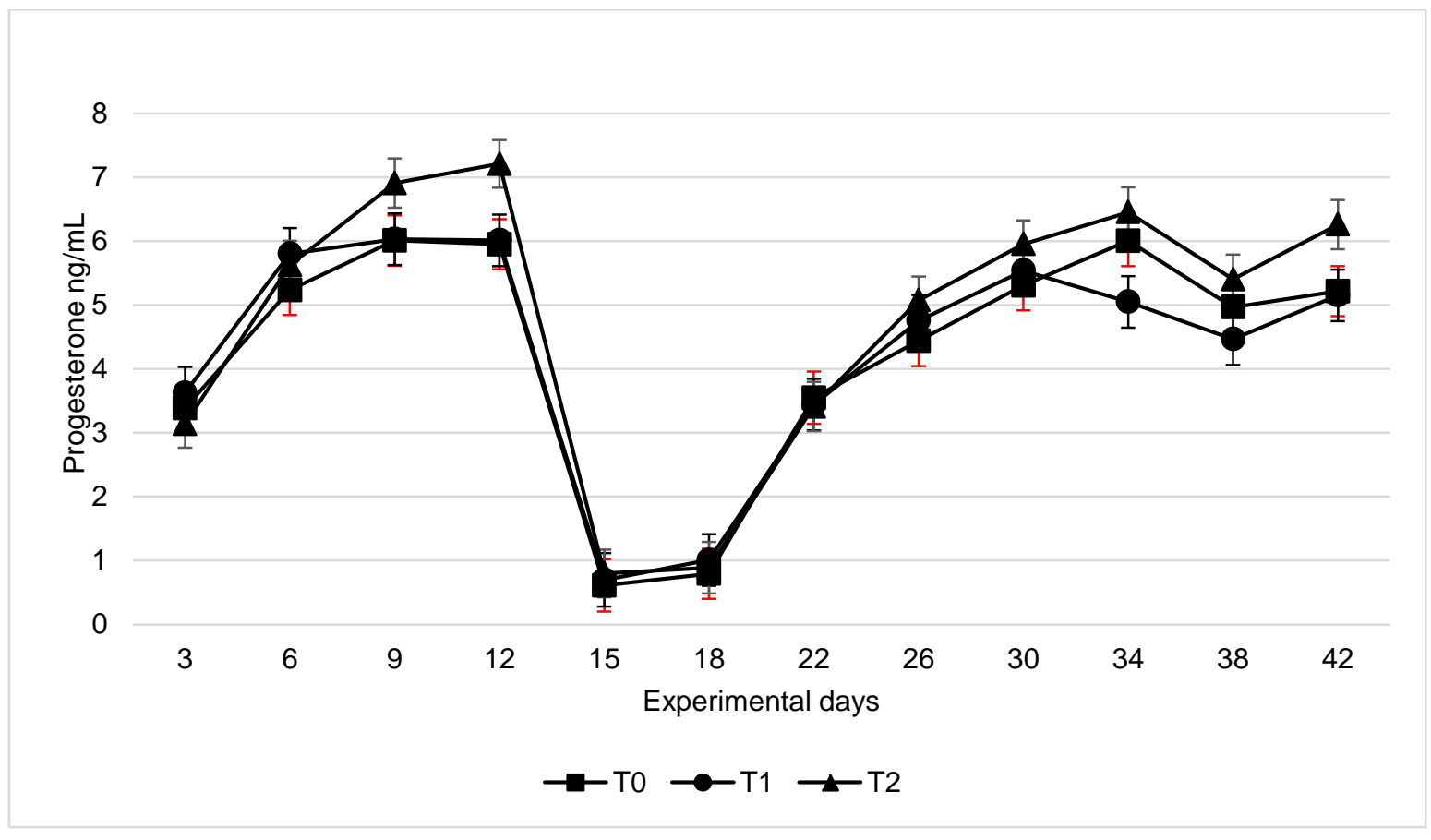

Figure 7 Progesterone concentration in plasma of ewes supplemented with coated vitamin C during oestrus synchronization and start of pregnancy

Sampling: 3 (CIDR insertion); 6 (3 days with CIDR); 9 (6 days with CIDR); 12 (application of PGF 2 ); 15 (detection of oestrus, mounts); 18 (one day of gestation); 22 (5 days of gestation); 26 (9 days of gestation); 30 (13 days of gestation); 34 (17 days of gestation); 38 (21 days of gestation); 42 (25 days of gestation).

TO: $0 \mathrm{~g}$ of vitamin C; T1: $3 \mathrm{~g}$ of vitamin C; T2: $6 \mathrm{~g}$ of vitamin C

CIDR: vaginal progesterone-releasing device

\section{Discussion}

In the present study it was found that dietary supplementation with $3 \mathrm{~g}$ and $6 \mathrm{~g}$ of vitamin $\mathrm{C}$ coated with ethylcellulose did not modify the reproductive responses of ewes.

Although plasma concentration of vitamin $C$ increased relative to the control when the ewes were supplemented with $3 \mathrm{~g}$ vitamin $\mathrm{C}(P<0.05)$, there was no further increase $(P>0.05)$ in concentration when supplemented with $6 \mathrm{~g}$. According to Padilla et al. (2007) the concentration of vitamin C in plasma is affected by urinary excretion. These authors determined that the renal threshold of vitamin $\mathrm{C}$ in cows is exceeded when supplemented at $20 \mathrm{mg}$ vitamin $\mathrm{C} / \mathrm{kg}$ of body weight. Therefore, when it is supplemented, vitamin C excretion is limiting its plasma concentration in response to consumption.

Hidiroglou et al. (1994) found that vitamin C is rapidly destroyed in the rumen of cows. However, when cows were supplemented with protected vitamin $\mathrm{C}$, it could be absorbed and its concentration in blood plasma would be increased. This was corroborated in the present study: supplementation with $3 \mathrm{~g}$ of vitamin C coated with ethylcellulose increased its concentration in plasma. However, no further increase was observed when supplemented with $6 \mathrm{~g}$ vitamin $\mathrm{C}$. Therefore, it is necessary to determine the appropriate dose of vitamin C supplementation, which the authors assume to be less than $3 \mathrm{~g}$ per sheep. When compared with other species such as humans, in which the recommended dose is $75 \mathrm{mg} / \mathrm{d}$ (Levine et al., 2001), the suggested dose in sheep could be high, because some of the vitamin C, although coated, could be degraded in the rumen. The requirements for vitamin $C$ in sheep remain unclear.

At the beginning of pregnancy, vitamin C concentration decreases in the blood of sheep (Salinas et al., 2017). Although its supplementation prior to breeding and during early gestation increased the concentration of vitamin $\mathrm{C}$ in blood plasma, and supplementation at $3 \mathrm{~g}$ improved the antioxidant status of the sheep, no improved responses in the percentages of pregnancy, prolificacy, fecundity and weight of the litter at birth were observed. This may be because the concentrations of vitamin C in the food or its synthesis in control sheep were 
sufficient to obtain an adequate reproductive response. The percentage of pregnancy was similar compared with other studies.

Omontese et al. (2017) administered ascorbic acid (75 mg, intramuscular) in sheep, at the time of insertion of the sponges and CIDRs, in a programme of oestrous synchronization. These authors reported $91.6 \%$ of gestation in treated ewes, which could indicate that the sheep were in optimal reproductive conditions. Therefore, it would be necessary to evaluate supplementation of vitamin C in sheep under oxidative stress situations, because it has been shown to affect the endocrine status and therefore reproductive variables such as duration of oestrous, follicular development and initial development of the embryo. In chickens, supplementation with vitamin $\mathrm{C}$ improved the characteristics of the egg (production, weight, thickness of the shell and the percentage of yolk) (Ciftci et al., 2005), and in rabbits it increased the size and weight of the litter at birth and weaning (Yassein et al., 2008). In mice vitamin E improved the average weight of the foetus and the placenta (Al-Enazi, 2007). In all the experiments the animals underwent energetic stress, and the authors reported that antioxidant vitamin supplementation improved reproductive performance.

Salinas et al. (2016) pointed out that by adjusting the consumption and synthesis of antioxidants, antioxidant capacity is modified. In the present study, presynchronization assured that all ewes were in the same physiological stage. Therefore, the greater antioxidant capacity in T1 was in response to the supplementation with $3 \mathrm{~g}$ of vitamin C. However, in T2 $6 \mathrm{~g}$ of the vitamin did not increase the antioxidant capacity significantly. A daily oral dose of vitamin C ( $3 \mathrm{~g}$ or more) can help to relieve oxidative stress and improve pregnancy rates and the weight of the lamb at birth (Hashem et al., 2016). In humans, oxidative stress increases the concentration of malonaldehyde (MDA) during the middle phase of the corpus luteum development, coinciding with maximum steroidogenic capacity (Vega et al., 1994). However, in the present study no differences were observed ( $P$ $>0.05$ ). Nevertheless, the rapid depletion of antioxidant vitamins in plasma and the increase in MDA concentrations during reproduction could be a consequence of the intensive steroidogenesis and cyclic activities of the ovaries. Consequently, the reduction of antioxidant vitamins could cause lipid oxidation in red blood cells, causing MDA to rise (Moore \& Roberts, 1998). Several authors concluded that the beginning of the ovarian cyclic activity during the breeding season and early gestation results in oxidative stress and therefore a greater demand for antioxidant vitamins in the reproductive tissues (Mohebbi-Fani et al., 2012).

In the present research, no differences $(P<0.05)$ were observed between treatments or sampling when determining lipoperoxidation in plasma. In a study with male rats it was observed that as the concentration of ascorbic acid in blood serum increased in treated animals, and lipoperoxidation levels decreased (Sonmez et al., 2005).

Oxidative stress increases during early pregnancy owing to the metabolic processes that are necessary for the formation of the placenta. For that reason, as pregnancy progresses, the placental transfer of vitamins A, $C, E$ and some of the B group (Mohebbi-Fani et al., 2012) and minerals increases with time to balance the effects of reactive oxygen species (Hidiroglou et al., 1994). This was observed in the last ascorbic acid sampling in which the highest levels were obtained in all treatments. At this time, the most demanding physiological stages, such as synchronization of oestrus, breeding and maternal recognition of pregnancy, had already passed, whereby the use of antioxidants had decreased, resulting in an increase in plasma vitamin C concentration.

In the present research, the addition of vitamin $C$ did not modify progesterone concentration in any of the samples. A high requirement of ascorbic acid is necessary to facilitate the production of progesterone (Luck \& Zhao, 1993). Progesterone is the main hormone that is responsible for maintaining pregnancy and its decrease at early gestation could trigger abortions (Diskin \& Morris, 2008). During pregnancy, a continuous secretion of progesterone is required to provide an appropriate uterine environment for the maintenance of gestation (Niswender et al., 2000). In a study conducted with Holstein cows, no correlation was observed between the concentration of vitamin $C$ and plasma progesterone levels (Ataman et al., 2009).

Ruminants can synthesize vitamin C from carbohydrate precursors, including glucose. Glucose is the primary nutrient for embryo growth and milk synthesis, whereby nutritional requirements are increased during pregnancy, especially if there is more than one foetus (Bell \& Bauman, 1997). The increase it needs is because the foetus can consume $60 \%$ to $70 \%$ of the mother's glucose production and $70 \%$ of the weight of the lamb at birth is obtained in the last six weeks of pregnancy. This stage is critical since nutritional requirements of sheep are not always satisfied, and those deficiencies must be compensated from bodily reserves. Nevertheless, there is evidence that nutritional deficiencies during early gestation have serious effects on gestation (Spencer \& Bazer, 2004), and on postnatal growth and health (Gao et al., 2009). 
In a study carried out on Santa Inés sheep which were synchronized with sponges (Progespon®), average glucose levels of $64.8 \mathrm{mg} / \mathrm{dL}$ were recorded during the summer and winter seasons (Balaro et al., 2015). On the other hand, MacLeod et al. (1999) indicated that a low synthesis of ascorbic acid is observed in high-producing cows as a result of high glucose demands of the body, especially during the beginning of lactation. In this study, the lower glucose concentration on ewes supplemented with $3 \mathrm{~g}$ vitamin $\mathrm{C}$ per day was due to different undetermined factor, since all diets were isoproteic and isoenergetic, and all the ewes were in the same reproductive stage. Similarly, the ewes in the present research were in a good body condition, which caused insulin and glucose levels to remain stable (Sosa et al., 2006).

\section{Conclusion}

Oral supplementation of $3 \mathrm{~g}$ and $6 \mathrm{~g}$ of coated vitamin $\mathrm{C}$ in ewes during oestrous synchronization, breeding and early gestation increased plasma vitamin C concentrations and improved antioxidant capacity without affecting the reproductive variables, progesterone and insulin concentrations. However, more research is required to determine additional benefits and the specific stages in reproduction where vitamin $\mathrm{C}$ supplementation would be most effective.

\section{Authors' Contributions}

KPP was a graduate student (master's degree) in the project. TST, TSR, MMCG, CNC, JLCM, JLFV, MMA were in charge of the project design and project implementation. All co-authors participated in management and discussion of the results, statistical analysis and writing, and corrected the manuscript. MCL ran the hormonal and glucose analysis.

\section{Conflict of Interest Declaration}

There are no conflicts of interest.

\section{References}

Al-Enazi, M.M., 2007. Influence of alpha tocopherol on heat stress-induced changes in the reproductive function of Swiss albino mice. Saudi J. Biol. Sci. 14(1), 61-67.

Al-Gubory, K.H., Fowler, P.A. \& Garrel, C., 2010. Roles of cellular reactive oxygen species, oxidative stress and antioxidants in pregnancy outcomes. Int. J. Biochem. Cell Biol. 42, 1634-1650.

Ataman, M.B., Erdem, H., Bülbül, B., Haliloğlu, S., Çınar, M. \& Aköz, M., 2010. Plasma $\beta$-carotene, vitamin A and vitamin C levels in cyclic and pregnant cows. Kafkas. Univ. Vet. Fak. Derg. 16(4), 579-584.

Balaro, M.F.A., Brandão, F.Z., Peneiras, A.B.V., Oba, E., da Fonseca, J.F., Almosny, N.R.P. \& da Cruz Cardoso, E., 2015. Reproductive performance, metabolic and hormonal profiles of Santa Inês ewes in winter and summer under tropical conditions. Trop. Anim. Health Prod. 47, 627-631.

Bell, A.W. \& Bauman, D.E., 1997. Adaptations of glucose metabolism during pregnancy and lactation. J. Mammary Gland Biol. Neoplasia 2(3), 265-278.

Benzie, I.F. \& Strain, J.J., 1999. Ferric reducing/antioxidant power assay: Direct measure of total antioxidant activity of biological fluids and modified version for simultaneous measurement of total antioxidant power and ascorbic acid concentration. Methods Enzymol. 299, 15-27.

Casamassima, D., Palazzo, M., Martemucci, G., Vizzarri, F. \& Corino, C., 2012. Effects of verbascoside on plasma oxidative status and blood and milk production parameters during the peripartum period in Lacaune ewes. Small Rumin. Res. 105, 1-3.

Ciftci, M., Ertas, O.N. \& Guler, T., 2005. Effects of vitamin E and vitamin C dietary supplementation on egg production and egg quality of laying hens exposed to a chronic heat stress. Rev. Med. Vet.156, 107-111.

Combs, G.F., 2008. Vitamin C. In: G.F. Combs (ed.). The Vitamins: Fundamental Aspects in Nutrition and Health. Third edition. Elsevier, San Diego, CA, USA.

Diskin, M.G. \& Morris, D.G., 2008. Embryonic and early foetal losses in cattle and other ruminants. Reprod. Domest. Anim. 43, 260-267.

Dobson, H., Fergani, C., Routly, J.E. \& Smith, R.F., 2012. Effects of stress on reproduction in ewes. Anim. Reprod. Sci. 130 (3-4), 135-140.

Gao, H., Wu, G., Spencer, T.E., Johnson, G.A., Li, X. \& Bazer, F.W., 2009. Select nutrients in the ovine uterine lumen. I. Amino acids, glucose, and ions in uterine lumenal flushings of cyclic and pregnant ewes. Biol. Reprod. 80, 86-93.

Garcia, E., 2004. Modifications to the system Köppen climate classification. 5th edition. Book series number 6 . Institute of Geography, Universidad Autónoma de México.

Hashem, N.M., Abd-Elrazek, D., Abo-Elezz, Z.R. \& Latif, M.G.A., 2016. Effect of vitamin A or C on physiological and reproductive response of Rahmani ewes during subtropical summer breeding season. Small Rumin. Res. 144, 313-319.

Hidiroglou, M., Batra, T.R. \& Roy, G.L., 1994. Changes in plasma a-tocopherol and selenium of gestating cows fed hay or silage. J. Dairy Sci. 77, 190-195. 
Jacota, S.K. \& Dani, H.M., 1982. A new colorimetric technique for the estimation of vitamin c, using Folin phenol reagent. Anal. Biochem. 127-128.

Leite, G.A.A., Figueiredo, T.M., Sanabria, M., Dias, A.F.M.G., Silva, P.V.E., ..., Kempinas, W.G., 2017. Ascorbic acid supplementation partially prevents the delayed reproductive development in juvenile male rats exposed to rosuvastatin since prepuberty. Reprod. Toxicol. 73, 328-338.

Levine, M., Wang, Y., Padayatty, S.J. \& Morrow, J., 2001. A new recommended dietary allowance of vitamin C for healthy young women. Proc. Natl. Acad. Sci. 98(17), 9842-9846.

Luck, M.R. \& Zhao, Y., 1993. Identification and measurement of collagen in the bovine corpus luteum and its relationship with ascorbic acid and tissue development. J. Reprod. Fert. 99(2), 647-652.

MacLeod, D.D., Zhang, X., Kennelly, J.J. \& Ozimek, L., 1999. Ascorbyl-2 polyphosphate as a source of ascorbic acid for dairy cattle. Milchwissenschaft 54, 123-126.

Mohebbi-Fani, M., Mirzaei, A., Nazifi, S. \& Shabbooie, Z., 2012. Changes of vitamins A, E, and C and lipid peroxidation status of breeding and pregnant sheep during dry seasons on medium-to-low quality forages. Trop. Anim. Health Prod. 44, 259-265.

Moore, K. \& Roberts, L.J., 1998. Measurement of lipid peroxidation. Free Radic. Res. 28, 659-671.

Niswender, G.D., Juengel, J.L., Silva, P.J., Rollyson, M.K. \& Mclntush, E.W., 2000. Mechanisms controlling the function and life span of the corpus luteum. Physiol. Rev. 80, 1-29.

NRC, National Research Council, 1985. Nutrient Requirements of Sheep. Sixth revised edition. National Academy Press, Washington DC, USA.

Ohkawa, H., Ohishi, N. \& Yagi, K., 1979. Assay for lipid peroxides in animal tissues by thiobarbituric acid reaction. Anal. Biochem. 95, 351-358.

Omontese, B.O., Adewuyi, A.B., Rekwot, P.I., Nwannenna, A.I. \& Rwuaan, J.S., 2017. Effect of ascorbic acid on the conception rate of Yankasa ewes after estrus synchronization. Rev. Elev. Med. Vet. Pays Trop. 70, 9-12.

Padilla, L., Matsui, T., Ikeda, S., Kitagawa, M. \& Yano, H., 2007. The effect of vitamin C supplementation on plasma concentration and urinary excretion of vitamin C in cattle. J. Anim. Sci. 85, 3367-3370.

Rong-Zhen, Z. \& Dao-Wei Z., 2013. Oxidative stress and role of natural plant derived antioxidants in animal reproduction. J. Integr. Agric. 12, 1826-1838.

SAGARPA, Secretaría de Agricultura, Ganadería, Desarrollo Rural, Pesca y Alimentación. 2001. Norma Oficial Mexicana NOM-062-ZOO-1999, Especificaciones técnicas para la producción, cuidado y uso de los animales de laboratorio. Diario Oficial de la Federación. 75, 113-160. (in Portuguese)

Salinas, R.T., Sánchez, T.E.M.T., Díaz, C.A., Cordero, M.J.L., Guinzberg, P.R., Rabanales, M.J.L., Figueroa, V.J.L. \& Hernández, B.J., 2017. Oxidative state of ewes with different number of parity during gestation y lactation. Pesq. Vet. Bras. 37, 1405-1410.

Salinas-Rios, T., Torres-Esqueda, M.T., Díaz-Cruz A., Cordero-Mora, J.L., Hernández-Bautista, J., Nava-Cuellar, C. \& Nieto, A.R., 2016. Oxidative status and fertility of ewes supplemented coffee pulp during estrous synchronization and early pregnancy. Rev. Colomb. Cienc. Pec. 29, 255-263.

SAS, 2002. Statistical Analysis System. SAS Institute Incorporation. Cary, NC, USA.

Sönmez, M., Türk, G. \& Yüce, A., 2005. The effect of ascorbic acid supplementation on sperm quality, lipid peroxidation and testosterone levels of male Wistar rats. Theriogenol. 63, 2063-2072.

Sosa, C., Abecia, J.A., Forcada, F., Vinoles, C., Tasende, C., Valares, J.A. \& Meikle, A., 2006. Effect of undernutrition on uterine progesterone and oestrogen receptors and on endocrine profiles during the ovine oestrous cycle. Reprod. Fert. Develop. 18, 447-458.

Spencer, T.E. \& Bazer, F.W., 2004. Uterine and placental factors regulating conceptus growth in domestic animals J. Anim. Sci. 82, 4-13.

Thomas, F.H., Leask, R., Sršen, V., Riley, S.C., Spears, N. \& Telfer, E.E., 2001. Effect of ascorbic acid on health and morphology of bovine preantral follicles during long-term culture. Reprod. 122, 487-495.

Vega, M., Devoto, L., Castro, O. \& Kohen, P., 1994. Progesterone synthesis by human luteal cells: Modulation by estradiol. J. Clin. Endocrinol. Metab. 79, 466-469.

Yassein, S.A., Mahmoud, K.G.M., Maghraby, N. \& Ezzo, O.H., 2008. Hot climate effects and their amelioration on some productive and reproductive traits in rabbit does. World Rabbit Sci. 16, 2008-7.

Yousef, M.I., Abdallah, G.A. \& Kamel, K.I., 2003. Effect of ascorbic acid and vitamin E supplementation on semen quality and biochemical parameters of male rabbits. Anim. Reprod. Sci. 76, 99-111. 